\title{
Beobachtung del Sonnenfinsterniss 1884 März 26
}

auf der Sternwarte in Helsingfors.

\begin{tabular}{clll}
\multicolumn{2}{c}{ Eintritt des Mondes } & \multicolumn{1}{c}{ Austritt } & Beobachter \\
M. Z. Hels. $18^{\mathrm{h}} 59^{\mathrm{m}} 5^{\mathrm{s}}$ & $19^{\mathrm{h}} \mathbf{4 2}^{\mathrm{m}} 13^{\mathrm{s}}$ & Donner \\
\# & $185^{8} 4^{8}$ & $194^{2} 3^{1}$ & Mag. G. Dreijer \\
, & & $194^{2} 8$ & Stud. K. Eklund
\end{tabular}

\begin{tabular}{lr}
\multicolumn{1}{c}{ Fernrohr } & Vergr. \\
Heliometer von $\mathbf{7 1}^{\mathrm{mm}}$ & 200 \\
Fernrohr von $57^{\mathrm{mm}}$ & 76 \\
Refractor von $174^{\mathrm{mm}}$ & 145
\end{tabular}

Die Luft war während der Beobachtung sehr gut und ruhig, der Himmel ganz ohne Wolken.

Helsingfors 1883 März 27.

Anders Donner.

\section{Observations of Comet Pons-Brooks}

made at the Halsted Observatory, Princeton N.J., with the 23 inch Equatorial.

\section{Communicated by Professor C.A. Young.}

The observations of position were made by Professor Young, except those of Dec. $2^{\text {th }}$ which were by $\mathrm{Mr}$. Mc. Neill. The filar-micrometer was used, with bright wires and a power of about 160 . On Jan. $16^{\text {th }}$ and $17^{\text {th }}$ however the observations were made by twilight, without artificial illumination, and consisted in measurements of distance, and position-angle, the position-zero being determined after the observations. In all other cases differences of $\alpha$ and $\delta$ were measured. In reducing the star-places to 1883.0 the tables of $m$ and $n$ employed were those given in Oppolzer's - Lehrbuch der Bahnbestimmungen e (vol. I, 2d Ed.), which are based on Struve's Constants. The comparison-stars on Jan. $16^{\text {th }}$ and $17^{\text {th }}$ were very small, not much above the $10^{\text {th }}$ magnitude, and have not been identified.

The reductions and computations have all been made by Mr. Mc. Neill.

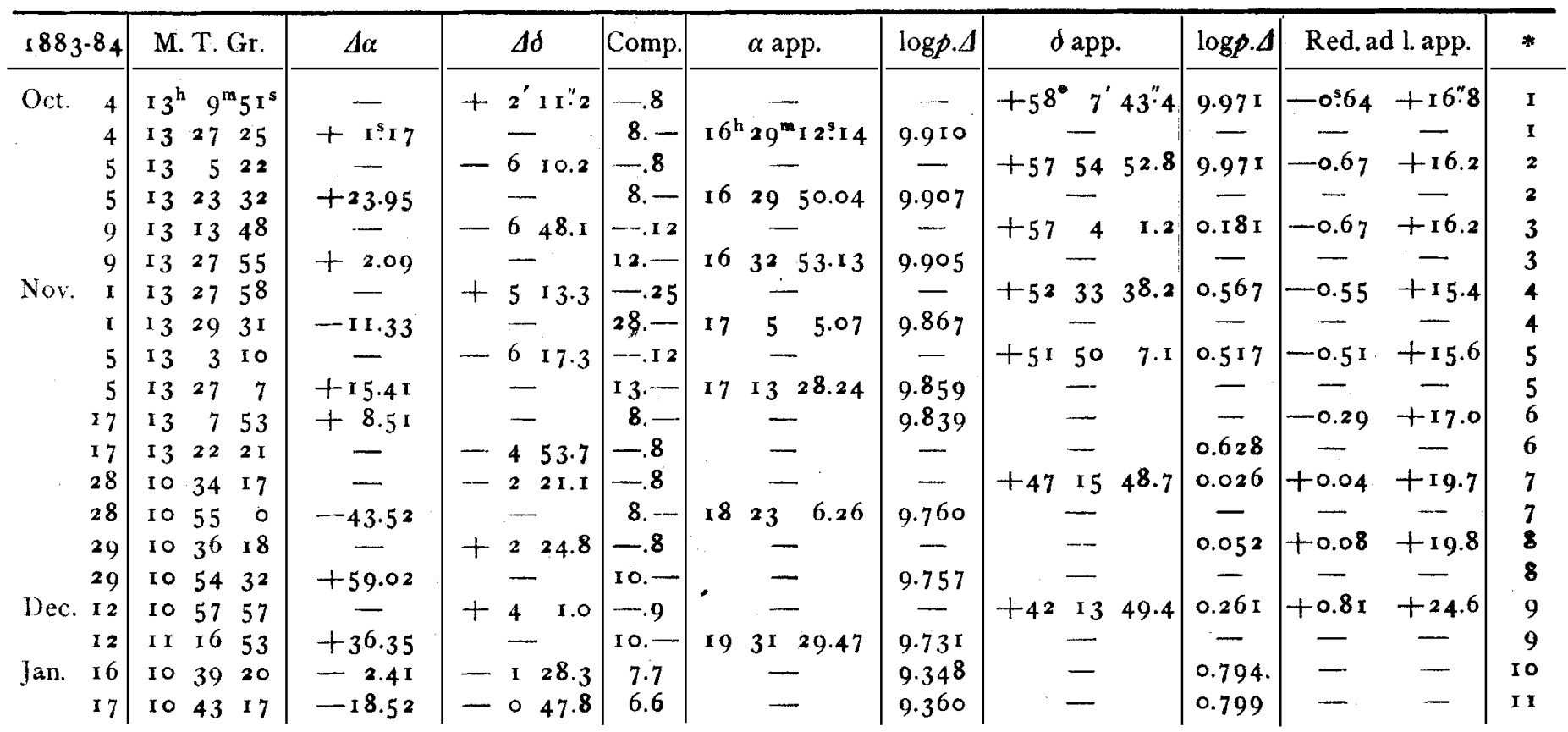

Mean Places of Comparison Stars.

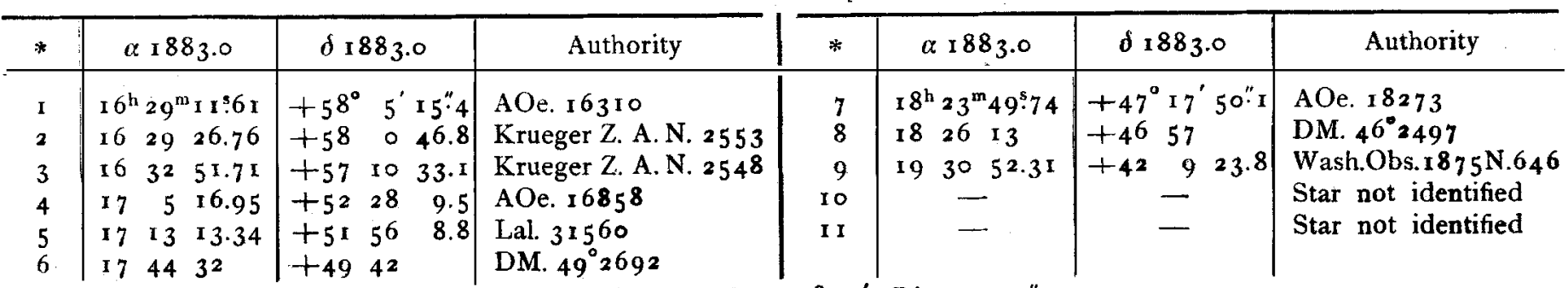

Star 2 is double, Mag. 8 and 9.5, Position angle $219^{\circ} 35^{\prime}$, Distance 1.55 . 
The comet was observed on several other nights when no stars good for comparison were near enough, the field with the lowest power being only $15^{\prime}$ in diameter. For the last two months the weather has been very bad, there having been no nights when the seeing was really good, and only a few when anything at all could be seen.

A few notes on the physical observations are appended. 1883 Sept. $514^{\text {h }}$ Greenw. M. T. Comet first found. Very faint, with slight central condensation. Diameter $\mathrm{I}^{1} / \mathbf{2}^{\prime}$ or 2', but having no very definite outline and no tail.

Sept. 26. Diameter of nebulosity $2^{\prime} 46^{\prime \prime}$. A faint streak visible in nebulosity at position angle $6 x^{\circ}$, probably. the beginning of a tail.

Oct. I. Tail about $8^{\prime}$ long: position angle $57^{\circ}$. Nucleus almost stellar.

Oct. 2. Nucleus throws off small brush towards the sun. Tail brighter on southern edge: position angle $66^{\circ}$.

A small direct-vision spectroscope, without slit, shows two knots in the spectrum of the nucleus. Comet too faint for spectroscope with slit.

Oct. 3. 'Tail about 5 ' long, position angle $59^{\circ}$. Diameter of comet's head measures $57^{\prime \prime}$. Faint brush toward sun. Too faint for spectroscope; sky hazy.

Oct. 5. Comet fainter; tail hardly visible.

Oct. 24. Comet round; no tail. Nucleus stellar, like a star $91 / 2$ magnitude.

Nov. I. Comet found in strong twilight. Nucleus 81.. mag.

Nov. 5. A faint brush, like an incipient tail, at $50^{\circ}$ position-angle: very faint and indistinct.

Nov. 7. Tail unmistakable, but faint: position-angle $50^{\circ}$. Nucleus much condensed, but hardly stellar; total brightness about $7 \frac{1}{2}$ magnitude.

Nov. 29. At $I^{\mathrm{h}} 5^{\mathrm{m}}$ Greenw. M. T. Comet passed within $2^{\prime \prime}$ or $3^{\prime \prime}$ of star of $\mathrm{I}^{\text {th }}$ magnitude, without any visible effect upon star's appearance. Comet flattened out and better defined on side next sun, the major axis of the nebulosity being at right angles to the sun's direction and about twice the minor axis; tail straight and pointing from sun; the whole form like this: $T$

Dec. 28. Spectrum of Comet observed with Grubb spectroscope and two prisms. Spectrum of the ordinary type: the nucleus-spectrum rather more nearly continuous than usual with comets.

I 884 Jan. 3. Used Clark spectroscope with one prism. Comet spectrum very fine. Three bands and a faint knot in the purple. The principal band in the green rather brighter in proportion to the others than ordinary, and broken into at least three, perhaps four or five, lines or narrow bands. Spectrum of the nucleus nearly continuous, but widened at the bands. No dark lines visible. With lowest eyepiece (power about I 20) the appearance of the comet is very striking. The nucleus is about $6 \frac{1}{2}$ magnitude, reddish and nearly stellar. There are 4 or 5 brushes directed toward the sun, each $20^{\prime \prime}$ or $30^{\prime \prime}$ long. "The tail near the head is cut out a little on the north side.

With field glass the tail is $4^{\circ}$ long and nearly straight. Moon 4 days old, not far away.

Jan. 4. Comet's head shows three curved jets.

Jan. I6. Comet found in twilight, nucleus stellar, but with several brushes directed to sun. No tail visible in the 23 inch; but as seen in field-glass, it was conspicuous, and $4^{\circ}$ long. Spectrum of nucleus nearly continuous: only very slightly knotted where it crosses the hydrocarbon bands.

Jan. I 7. With low power the comet shows a bright and pretty well defined sector on east side of nucleus, nearly at right angles to the general trend of the tail. Tail now easily seen in large telescope, being much better defined on southern than on northern edge. In field glass the tail is $6^{\circ}$ long. Comet estimated as equal to star of $2^{1 / 2}$ magnitude.

Stormy weather prevented any further observations.

Princeton N. J. 1884 February.

\section{Beobachtungen des Cometen Pons-Brooks}

angestellt von B. von Engelhardt am Fadenmicrometer des Aequatoreals (von iz" engl. Oeffnung) seiner Privatsternwarte zu Dresden.

(Fortsetzung von Nr. 2547 und Nr. 2560 der Astr. Nachr.)

\begin{tabular}{|c|c|c|c|c|c|c|c|c|c|c|}
\hline $188_{3} \cdot 84$ & M.Z. Dresd. & $\Delta \alpha$ & $\Delta \delta$ & Vergl. & & $\alpha$ app. & $\log p .4$ & $\delta$ app. & $\log p \cdot A$ & * \\
\hline Nov, 9 & $7^{\mathrm{h}} 16^{\mathrm{m}} 23^{\mathrm{s}}$ & $+6^{m} 14^{: 65}$ & $+7^{\prime} 49: 0$ & 14.5 & 17 & $22^{m} \quad 5^{s}: 62$ & 9.762 & $+51^{\circ} 9^{\prime} 37^{\prime \prime} \cdot 8$ & $0.5^{22}$ & $\mathbf{I}$ \\
\hline ra & ro 19 & +131.33 & -227.0 & 3. I & 17 & 5025.30 & 9.666 & $+49 \times 55^{6.1}$ & $0.84 \mathrm{I}$ & 2 \\
\hline 24 & $6334^{\circ}$ & 一 135.70 & $-\circ 45.3$ & 24.8 & I 8 & 655.02 & 9.720 & +48 I5 18.2 & 0.497 & 3 \\
\hline 29 & 71022 & -427.43 & +128.0 & I 8.6 & I 8 & $26 \quad 24.86$ & 9.729 & $\begin{array}{lll}+47 & 3 & 4.4\end{array}$ & 0.592 & 4 \\
\hline Dec. 29 & 65929 & to 40.19 & +227.0 & 30.10 & $2 x$ & 2312.99 & 9.567 & 855.0 & 0.690 & 5 \\
\hline Jan. & $6 \quad 5045$ & +o 11.65 & -132.0 & 35.13 & 2 I & 4450.22 & 9.530 & +224333.8 & 0.710 & 6 \\
\hline 15 & $7 \quad 10$ & +124.25 & -1340.9 & 24.8 & 23 & 1731.21 & $9.45^{8}$ & - $241 \mathrm{I} 3.0$ & 0.846 & 7 \\
\hline 21 & $\begin{array}{lll}6 & 3^{6} & 5^{1}\end{array}$ & -058.11 & +31.8 & 2.I & 23 & $49 \quad 5.05$ & $9.4 \times \mathrm{I}$ & $\begin{array}{lll}-13 & 4 & 53.8\end{array}$ & $0.88 \mathrm{I}$ & 8 \\
\hline 25 & $6 \quad 26 \quad 32$ & to 33.05 & +325.4 & I 8.6 & 0 & 4.05 & 9.397 & $\begin{array}{ll}7 & 25.8\end{array}$ & 0.897 & 9 \\
\hline 25 & $\begin{array}{lll}6 & 40 & 1\end{array}$ & to 35.41 & +237.0 & $9 \cdot 3$ & o & $6.4 \mathrm{I}$ & 9.426 & 814.2 & 0.893 & 9 \\
\hline 25 & $\begin{array}{lll}6 & 49 & 29\end{array}$ & to 37.31 & +24.0 & 9.3 & o & $8.3 \mathrm{I}$ & 9.444 & 847.2 & 0.890 & 9 \\
\hline
\end{tabular}

